\title{
Stereoselective Synthesis of Isoxazolidines through Pd-Catalyzed Carboetherification of $\boldsymbol{N}$-Butenylhydroxylamines**
}

\author{
Michael B. Hay and John P. Wolfe*
}

Isoxazolidines are frequently used as intermediates in the synthesis of complex molecules ${ }^{[1]}$ and are found in several interesting biologically active compounds. ${ }^{[2]}$ In addition, the isoxazolidine $\mathrm{N}-\mathrm{O}$ bond can be easily cleaved under reducing conditions to afford 1,3-amino alcohols, which are also of synthetic utility. ${ }^{[3]}$ The most commonly employed method for the construction of isoxazolidines involves 1,3-dipolar cycloaddition reactions between nitrones and alkenes, ${ }^{[4]}$ which generates the $\mathrm{O} 1-\mathrm{C} 5$ bond and the $\mathrm{C} 3-\mathrm{C} 4$ bond in one step [Eq. (1)]. Although these transformations are very useful, many intermolecular cycloadditions of unactivated alkenes

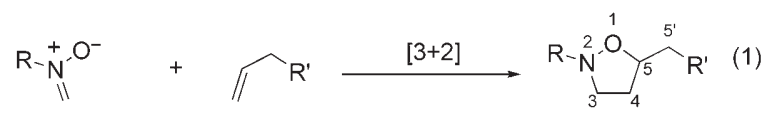

generate mixtures of regioisomers. ${ }^{[4]}$ Moreover, the major stereoisomers typically result from endo addition on the less hindered face of the alkene, and the selective preparation of stereoisomers resulting from exo addition and/or addition to the more substituted alkene face cannot be achieved in a straightforward manner. ${ }^{[4]}$

Herein, we describe a new approach to the construction of substituted isoxazolidines based on palladium-catalyzed carboetherification reactions of $\mathrm{N}$-butenyl hydroxylamine derivatives with aryl bromides [Eq. (2)]. This method represents a new strategy for construction of the isoxazolidine ring, in

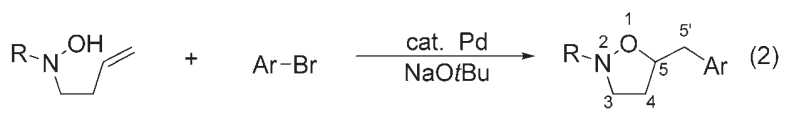

which the $\mathrm{O} 1-\mathrm{C} 5$ bond and a $\mathrm{C}^{\prime}-\mathrm{Ar}$ bond are formed in one step. ${ }^{[5]}$ These transformations also provide access to isoxazolidine stereoisomers that cannot be generated with currently

[*] M. B. Hay, Prof. J. P. Wolfe

University of Michigan

Department of Chemistry

Ann Arbor, MI 48109-1055 (USA)

Fax: (+1) 734-763-2307

E-mail: jpwolfe@umich.edu

[***] This research was supported by the NIH-NIGMS (GM-071650). J.P.W. thanks The Camille and Henry Dreyfus Foundation (New Faculty Award, Teacher Scholar Award) and Research Corporation for an Innovation Award. Additional unrestricted support was provided by Eli Lilly, 3M, and Amgen.

9 Supporting information for this article is available on the WWW under http://www.angewandte.org or from the author. available methods. The reactions appear to proceed by intramolecular alkene insertion into previously unprecedented palladium alkoxyamine intermediates, which may be of utility in other Pd-catalyzed carbon-heteroatom bondforming processes.

In preliminary experiments, we examined Pd-catalyzed reactions of $N$-butenyl hydroxylamines 1-3 with 4-bromobiphenyl under conditions that were employed in our prior studies on Pd-catalyzed carboetherification reactions of $\gamma$ hydroxyalkenes. ${ }^{[6-8]}$ As shown in Table 1, attempts to cyclize unprotected hydroxylamine substrate $\mathbf{1}$ and $N$-tert-

Table 1: Carboetherification of $\mathrm{N}$-butenyl hydroxylamines.

[a] Conditions: 1.0 equiv substrate, 1.2 equiv $\mathrm{ArBr}, 1.2$ equiv $\mathrm{NaOtBu}$, $2 \mathrm{~mol} \% \mathrm{Pd}(\mathrm{OAc})_{2}, 2 \mathrm{~mol} \%$ DPE-Phos, THF $(0.125 \mathrm{M}), 65^{\circ} \mathrm{C}$. [b] Yields represent average yields of isolated product for two or more experiments. [c] Heck arylation products were observed.

butyloxycarbonyl(Boc)-protected derivative 2 were unsuccessful. ${ }^{[9]}$ However, we were gratified to find that treatment of $N$-benzyl-protected substrate $\mathbf{3}$ with 4-bromobiphenyl and $\mathrm{NaO} t \mathrm{Bu}$ in the presence of catalytic amounts of $\mathrm{Pd}(\mathrm{OAc})_{2}$ and DPE-Phos ${ }^{[10]}$ afforded the desired product 4 in $80 \%$ yield.

With viable reaction conditions and a suitable nitrogen protecting group identified, we examined Pd-catalyzed carboetherification reactions between several different substituted hydroxylamines and a number of aryl bromides. As shown in Table 2, this method is effective with electron-rich (entry 10), electron-neutral (entries 4, 7, 8, and 12), electronpoor (entries 1, 2, 11, and 13), $o$-substituted (entry 8), and heterocyclic (entries 3, 5, 6, and 9) aryl bromides. In addition to the $N$-benzyl-protected derivatives described above, hydroxylamine substrates bearing $N$-methyl or $N$-tert-butyl groups also undergo cyclization in good yield.

The carboetherification reactions are also effective with substrates bearing substituents along the tether between the hydroxylamine moiety and the alkene. Transformations of these substrates provide access to disubstituted isoxazolidines with moderate to excellent stereocontrol. Importantly, in many cases these cyclizations provide a means to generate isoxazolidines that could not be prepared using 1,3-dipolar 
Table 2: Pd-catalyzed synthesis of substituted isoxazolidines. ${ }^{[a]}$

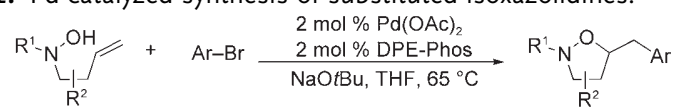

\begin{tabular}{|c|c|c|c|c|}
\hline Entry & Substrate & Isoxazolidine & d..$^{[b]}$ & Yield $[\%]^{[c]}$ \\
\hline 1 & & & - & 85 \\
\hline 2 & & & $>20: 1 \quad(5: 1)$ & 56 \\
\hline 3 & 5 & & $3: 1(3: 1)$ & 70 \\
\hline 4 & 5 & & $>20: 1 \quad(3: 1)$ & 57 \\
\hline 5 & & & $3: 1(3: 1)$ & 77 \\
\hline 6 & 6 & & $3: 1(3: 1)$ & 78 \\
\hline 7 & & & $3: 1(3: 1)$ & 61 \\
\hline 8 & & & $>20: 1(10: 1)$ & 82 \\
\hline 9 & 8 & & $>20: 1 \quad(10: 1)$ & 85 \\
\hline 10 & & & 19:1 (9:1) & 94 \\
\hline 11 & 9 & $\mathrm{Cl}$ & $>20: 1 \quad(9: 1)$ & 89 \\
\hline $12^{[\mathrm{d}]}$ & & & $>20: 1 \quad(>20: 1)$ & 78 \\
\hline $13^{[\mathrm{d}]}$ & 10 & & $>20: 1(>20: 1)$ & 69 \\
\hline
\end{tabular}

[a] Conditions: 1.0 equiv substrate, 1.2 equiv $\mathrm{ArBr}, 1.2$ equiv $\mathrm{NaOtBu}$, $2 \mathrm{~mol} \% \mathrm{Pd}(\mathrm{OAc})_{2}, 2 \mathrm{~mol} \%$ DPE-Phos, THF $(0.125 \mathrm{M}), 65^{\circ} \mathrm{C}$. [b] d.r. $=$ diastereomeric ratio of isolated material. Numbers in parentheses are the observed diastereomeric ratios for the crude reaction mixture. [c] Yields represent average yields of product isolated in two or more experiments. [d] The reaction was conducted at $110^{\circ} \mathrm{C}$ in toluene solvent with $\left[\mathrm{Pd}_{2}(\mathrm{dba})_{3}\right](1 \mathrm{~mol} \%)$ used in place of $\mathrm{Pd}(\mathrm{OAc})_{2}(\mathrm{dba}=$ dibenzylideneacetone).

cycloaddition methods. For example, Pd-catalyzed reactions of 10 with 4-bromobiphenyl and 3-bromobenzotrifluoride provide 22 and $\mathbf{2 3}$, respectively, in $78 \%$ and $69 \%$ yields, with $>20: 1$ diastereoselectivity and regioselectivity (Table 2, entries 12 and 13). In contrast, a 1,3-dipolar cycloaddition reaction between a nitrone and a 3-arylcyclopentene would be expected to occur on the less hindered face of the alkene to afford a different stereoisomer and would likely generate mixtures of regioisomers. ${ }^{[4]}$ In addition, reactions of $\mathbf{8}$ with aryl bromides proceed in $82-85 \%$ yield and $10: 1$ d.r. to afford the $\left(2 R^{*}, 3 \mathrm{a} S^{*}\right)$-hexahydropyrrolo[1,2b]isoxazole isomers 18 and 19 (Table 2, entries 8 and 9). However, dipolar cycloadditions between 3,4-dihydropyrrole-1-oxide and allylbenzene derivatives instead generate stereoisomeric $\left(2 S^{*}, 3 \mathrm{a} S^{*}\right)$ hexahydropyrrolo[1,2b]isoxazoles. ${ }^{[1]]}$ The hydroxylamine carboetherifications can also be used to prepare trans-4,5disubstituted isoxazolidines 12-14 and cis-3,5-disubstituted isoxazolidines 15-17 in good yield with $3: 1$ to $5: 1$ diastereoselectivity.

A plausible mechanism for the isoxazolidine-forming reactions is shown in Scheme 1 . These transformations appear to be mechanistically related to Pd-catalyzed carbo-

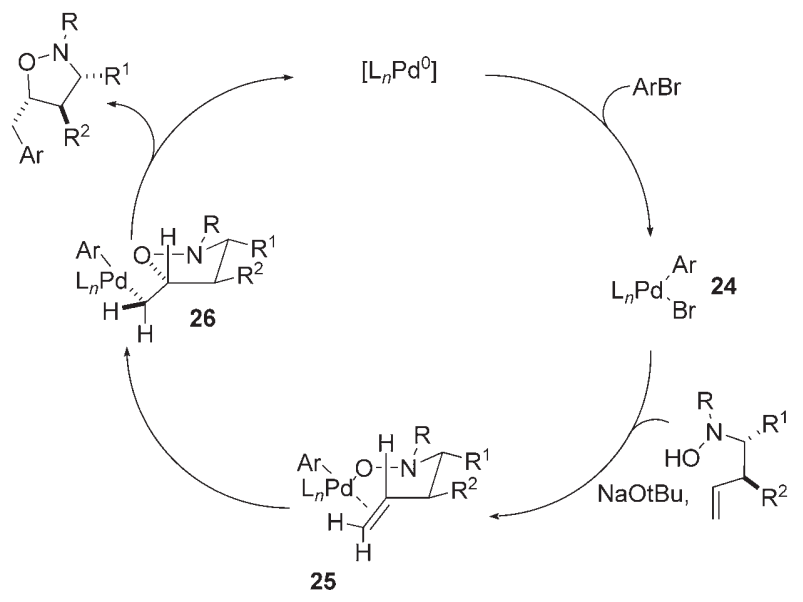

Scheme 1. Catalytic cycle of the Pd-catalyzed carboetherification reaction of $\mathrm{N}$-butenylhydroxylamines.

etherification reactions of $\gamma$-hydroxy alkenes with aryl bromides $^{[6]}$ and are likely initiated by oxidative addition of the aryl bromide to $\mathrm{Pd}^{0}$ to afford 24. The $\left[\mathrm{L}_{n} \mathrm{Pd}(\mathrm{Ar})(\mathrm{Br})\right]$ complex can then be transformed to intermediate $\mathbf{2 5}$ by reaction with the hydroxylamine substrate and $\mathrm{NaO} t \mathrm{Bu}$. Intramolecular syn oxypalladation ${ }^{[6,12]}$ of the tethered alkene moiety of $\mathbf{2 5}$ would generate $\mathbf{2 6}$, which can undergo $\mathrm{C}-\mathrm{C}$ bond-forming reductive elimination ${ }^{[13]}$ to afford the observed isoxazolidine products. The conversion of $\mathbf{1 0}$ to syn-addition products 22 and $\mathbf{2 3}$ is consistent with this hypothesis. Moreover, this model also accounts for the observed stereochemistry of 12-21, as the syn oxypalladation likely occurs from an organized cyclic transition state in which nonbonding interactions are minimized by pseudoequatorial orientation of the substrate $\mathrm{R}^{1}$ and $\mathrm{R}^{2}$ groups. This transition state arrangement would provide cis-3,5-disubstituted products $\left(\mathrm{R}^{2}=\mathrm{H}\right)$ and trans-4,5-disubstituted compounds $\left(\mathrm{R}^{1}=\mathrm{H}\right)$.

Although palladium(aryl)alkoxides have been shown to be important intermediates in a number of catalytic processes, ${ }^{[6,14,15]}$ the analogous complexes derived from hydroxylamines (e.g. 25) are unknown. The reactions described in this paper represent the first examples of catalytic transforma- 
tions involving $\left[\mathrm{Pd}(\mathrm{Ar})\left(\mathrm{ONRR}^{\prime}\right)\right]$ species. These previously unknown intermediates will likely find additional applications in other metal-catalyzed carbon-heteroatom bond-forming reactions. ${ }^{[15]}$

In conclusion, we have developed a new stereoselective method for the construction of substituted isoxazolidines through Pd-catalyzed carboetherification reactions of unsaturated hydroxylamine substrates. In many cases the stereochemical outcome of these transformations is complementary to that of nitrone cycloadditions, and this method provides a new strategic disconnection that can be used for retrosynthetic analysis of substituted isoxazolidines.

Received: March 30, 2007

Published online: July 26, 2007

Keywords: aryl halides - homogeneous catalysis . nitrogen heterocycles · olefin insertion · palladium

[1] For a review on the use of isoxazolidines as intermediates in complex molecule synthesis, see: M. Frederickson, Tetrahedron 1997, 53, $403-425$.

[2] a) H. Ishiyama, M. Tsuda, T. Endo, J. Kobayashi, Molecules 2005, 10,312-316; b) A. R. Minter, B. B. Brennan, A. K. Mapp, J. Am. Chem. Soc. 2004, 126, 10504-10505; c) G. C. Palmer, M. J. Ordy, R. D. Simmons, J. C. Strand, L. A. Radov, G. B. Mullen, C. R. Kinsolving, V. St. Georgiev, J. T. Mitchell, S. D. Allen, Antimicrob. Agents Chemother. 1989, 33, 895-905.

[3] a) S. M. Lait, D. A. Rankic, B. A. Keay, Chem. Rev. 2007, 107, 767-796; b) J. Revuelta, S. Cicchi, A. Brandi, Tetrahedron Lett. 2004, 45, 8375-8377; c) N. A. LeBel, N. Balasubramanian, $J$. Am. Chem. Soc. 1989, 111, 3363 -3368; d) H. Iida, K. Kasahara, C. Kibayashi, J. Am. Chem. Soc. 1986, 108, 4647-4648.

[4] For reviews on 1,3-dipolar cycloaddition reactions, see: a) P. N. Confalone, E. M. Huie, Org. React. 1988, 36, 1-173; b) K. V. Gothelf, K. A. Jorgensen, Chem. Commun. 2000, 1449-1458; c) S. Kanemasa, Synlett 2002, 1371-1387; d) A. E. Koumbis, J. K. Gallos, Curr. Org. Chem. 2003, 7, 585-628; e) P. Merino in Science of Synthesis (Houben-Weyl Methods of Molecular Transformations), Vol 27 (Ed.: A. Padwa), Thieme, Stuttgart, 2004, pp. 511-580; f) G. Pandey, P, Banerjee, S. R. Gadre, Chem. Rev. 2006, 106, 4484-4517; g) G. Molteni, Heterocycles 2006, 68, 2177-2202.

[5] A recent report described $\mathrm{Pd}^{0}$ - and $\mathrm{Pd}^{\mathrm{II}}$-catalyzed syntheses of 2vinyl isoxazolidines by cyclizations of hydroxylamines bearing tethered allylic acetate groups. In contrast to the reactions described in this paper, the cyclizations of the allyl acetate derivatives do not lead to $\mathrm{C}-\mathrm{C}$ bond formation concomitant with ring closure. The cyclizations of the allylic acetate derivatives are also mechanistically distinct, as the $\mathrm{Pd}^{0}$-catalyzed transformation proceeds via a $\pi$-allylpalladium intermediate which is likely captured by an outer-sphere nucleophilic attack on the allyl ligand, and the $\mathrm{Pd}^{\mathrm{II}}$-catalyzed transformation proceeds by alkene activation followed by outer-sphere anti-oxypalladation. No evidence exists for the intermediacy of $\left[\mathrm{L}_{n} \mathrm{Pd}\left(\mathrm{ONR}_{2}\right)(\right.$ allyl $\left.)\right]$ complexes that bear a $\mathrm{Pd}-\mathrm{O}$ bond. See: a) P. Merino, T. Tejero, V. Mannucci, G. Prestat, D. Madec, G. Poli, Synlett 2007, $944-$ 948. For additional discussion of Pd-catalyzed allylations of nucleophiles containing an $\mathrm{N}-\mathrm{O}$ bond, see: b) $\mathrm{H}$. Miyabe, K. Yoshida, V. K. Reddy, A. Matsumura, Y. Takemoto, J. Org. Chem. 2005, 70, 5630-5635.

[6] a) J. P. Wolfe, M. A. Rossi, J. Am. Chem. Soc. 2004, 126, $1620-$ 1621 ; b) M. B. Hay, A. R. Hardin, J. P. Wolfe, J. Org. Chem. 2005, 70,3099-3107; c) M. B. Hay, J. P. Wolfe, J. Am. Chem. Soc. 2005, 127, 16468-16476; d) M. B. Hay, J. P. Wolfe, Tetrahedron Lett. 2006, 47, 2793-2796.

[7] For a review on Pd-catalyzed carboetherification and carboamination reactions of $\gamma$-hydroxy and $\gamma$-amino alkenes, see: J. P. Wolfe, Eur. J. Org. Chem. 2007, 571-582.

[8] Two recent reports have described a related approach to the synthesis of cis-3,5-disubstituted isoxazolidines in which the N$\mathrm{C} 3$ bond is generated by Pd-catalyzed carboamination of $O$ homoallyl hydroxylamines. The scope of these transformations has not been fully explored. See: a) K. G. Dongol, B. Y. Tay, Tetrahedron Lett. 2006, 47, 927-930; b) J. Peng, W. Lin, S. Yuan, Y. Chen, J. Org. Chem. 2007, 72, 3145-3148.

[9] The major products observed in these reactions resulted from Heck arylation of the alkene.

[10] DPE-Phos = bis(diphenylphosphinophenyl)ether

[11] H. Iida, Y. Watanabe, C. Kibayashi, J. Chem. Soc. Perkin Trans. 1 1985, $261-266$.

[12] For other recent studies on syn alkene insertions into latetransition-metal oxygen bonds, see: a) H. E. Bryndza, J. C. Calabrese, S. S. Wreford, Organometallics 1984, 3, 1603-1604; b) M. A. Bennett, H. Jin, S. Li, L. M. Rendina, A. C. Willis, J. Am. Chem. Soc. 1995, 117, 8335-8340; c) O. Hamed, C. Thompson, P. M. Henry, J. Org. Chem. 1997, 62, 7082-7083; d) T. Hayashi, K. Yamasaki, M. Mimura, Y. Uozumi, J. Am. Chem. Soc. 2004, 126, 3036-3037; e) R. M. Trend, Y. K. Ramtohul, B. M. Stoltz, J. Am. Chem. Soc. 2005, 127, 1777817788; f) P. Zhao, C. D. Incarvito, J. F. Hartwig, J. Am. Chem. Soc. 2006, 128, 9642-9643.

[13] a) D. Milstein, J. K. Stille, J. Am. Chem. Soc. 1979, 101, 4981 4991; b) J. F. Hartwig, Inorg. Chem. 2007, 46, 1936-1947.

[14] For examples of well-characterized $\left[\mathrm{L}_{n} \mathrm{Pd}(\mathrm{Ar})(\mathrm{OR})\right]$ complexes, see: a) G. Mann, J. F. Hartwig, J. Am. Chem. Soc. 1996, 118, 13109-13110; b) R. A. Widenhoefer, H. A. Zhong, S. L. Buchwald, J. Am. Chem. Soc. 1997, 119, 6787-6795.

[15] In addition to carboetherification reactions of $\gamma$-hydroxyalkenes, synthetically useful reactions that are believed to proceed via $\left[\mathrm{L}_{n} \mathrm{Pd}(\mathrm{Ar})(\mathrm{OR})\right]$ complexes include Pd-catalyzed $O$-arylation reactions and oxidation reactions. It is likely that the analogous hydroxylamine complexes $\left[\mathrm{L}_{n} \mathrm{Pd}(\mathrm{Ar})\left(\mathrm{ONRR}^{\prime}\right)\right]$ will find similar applications. For lead references on useful catalytic transformations involving $\left[\mathrm{L}_{n} \mathrm{Pd}(\mathrm{Ar})(\mathrm{OR})\right]$ intermediates, see: a) A. V. Vorogushin, X. Huang, S. L. Buchwald, J. Am. Chem. Soc. 2005, 127, 8146-8149; b) N. Kataoka, Q. Shelby, J. P. Stambuli, J. F. Hartwig, J. Org. Chem. 2002, 67, 5553-5566; c) A. S. Guram, X. Bei, H. W. Turner, Org. Lett. 2003, 5, 2485-2487. 